\title{
RESEÑAS
}

\section{EL PENSAMIENTO URBANO EN LOS AÑOS RUGIENTES}

\author{
Adrián Gorelik* \\ * Universidad de Quilmes, Centro de História Intelectual, Buenos Aires, Argentina. \\ LEME, M. C. S. (org.). Urbanismo e política no Brasil dos anos 1960. São Paulo: \\ Annablume, 2019. ${ }^{1}$
}

Este libro es el cuarto que realiza la red de pesquisa urbanismobr desde que se estableció a comienzos de los años noventa. ${ }^{2}$ Vista de conjunto, esta producción colectiva sorprende por la capacidad de estructurar problemáticas para el resto del campo disciplinar -de hecho, la sensación de equipo que da este grupo se agiganta cuando se ven las decenas de trabajos en todo el país a los que les ha servido de inspiración y avanzada-, tanto como por la vocación de relevamiento sistemático de temas en escala nacional. Figuras de urbanista, ideas y nociones, planes, instituciones, políticas, en las ciudades mayores pero también en muchas menores, en el nivel nacional pero también en varios de los estados: todo eso ha sido trabajado de modo riguroso en Brasil para el dilatado ciclo urbano del "largo siglo XX" -y permítanme contradecir aquí la fórmula que Hobsbawm volvió célebre, ya que esta otra se ajusta mejor a las necesidades específicas de la historia de la ciudad y el urbanismo, que reconoce una continuidad desde el último tercio del siglo XIX

\footnotetext{
1. Este texto reelabora los comentarios sobre el libro que expuse en la presentación realizada en la Librería Tapera Taperá, Sao Paulo, 26 de octubre de 2019. Agradezco a Maria Cristina Leme y José Lira, que me invitaron a presentarlo y a escribir la reseña, y a Ana Castro, Anahi Ballent y el mismo Lira que contribuyeron con sus lecturas críticas al pasaje de la oralidad a la escritura.

2. Los tres libros anteriores son: Maria Cristina da Silva Leme (org.), Urbanismo no Brasil 1895-1965, São Paulo, Studio Nobel / FAUUSP / FUPAM, 1999; José Francisco Bernardino Freitas (org.), Diálogos: urbanismobr, Niterói, Eduff, 2010; Vera F. Rezende (org.), Urbanismo na Era Vargas: a transformação das cidades brasileiras, Niterói, EDUFF / Intertexto, 2012.
} 
hasta finales de la década de 1970: lo que Bernardo Secchi llamó la experiencia de la expansión, con consecuencias directas en el tema que vamos a abordar. ${ }^{3}$

Lo cierto es que no hay ningún otro país en la región en el que se haya cubierto el terreno de la investigación en historia del urbanismo de modo tan pleno y metódico. En Argentina sólo es posible avizorar el desarrollo de obras individuales, algunas realmente excelentes -entre las que sobresalen las de Alicia Novick y Ana María Rigotti-, pero que necesariamente se concentran en algunos temas, algunas ciudades y algunos períodos, dejando enormes lagunas sobre cuestiones muy importantes de las que todavía sabemos muy poco. ${ }^{4}$ Por ejemplo, una extraordinaria exposición sobre el Plan de la Comisión de Estética Edilicia para Buenos Aires de 1925, que presentó Rigotti a comienzos de 2019 en el Museo Fernández Blanco, nos enfrentó a la evidencia de que era la primera vez que se analizaba entre nosotros un plan urbano con tal detenimiento y proyección pública. ${ }^{5}$ Si bien no conozco tan bien la producción de otros países como la del mío, creo que se podrían afirmar cosas bastante similares sobre Uruguay, Chile, Perú, Colombia, México, donde los temas de historia del urbanismo estudiados y los investigadores que se dedican a ello son realmente escasos. O sobre Venezuela, de donde ha salido uno de los pocos historiadores del urbanismo de escala latinoamericana, Arturo Almandoz, y otro historiador notable, Juan José Martín Frechilla, ha estudiado estaciones completas del tema en ese país, pero el panorama general parece seguir siendo el resultado de iniciativas individuales, a mucha distancia de cualquier exploración sistemática. ${ }^{6}$ Por no hablar de la ausencia, en todos estos países, de historias generales

3. Eric Hobsbawm utilizó la fórmula del "siglo XX corto" en el título de su obra Extremes. The short twentieth century, 1914-1991, Londres, Michael Josephs Ltd., 1994 (en el prólogo atribuye el concepto a Iván Berend, historiador húngaro); Bernardo Secchi desarrolló su idea de un largo ciclo expansivo de la ciudad y el pensamiento urbano en "Le condizione sono cambiate", artículo de 1984 reunido en B. Secchi, Un progetto per l’urbanistica, Turín, Giuilio Einaudi, 1989.

4. El hecho de que estos dos referentes fundacionales de la historia del urbanismo aún no hayan publicado como libro sus tesis doctorales es, creo, un claro indicio de la escasa tensión del campo disciplinar en Argentina. Cierto es que ambas publican artículos asiduamente, y no sólo sobre historia del urbanismo, pero sus tesis son la clase de hitos que un campo en busca de constitución no deja escapar: Ana María Rigotti, "Las invenciones del urbanismo en la Argentina (1900-1960). Inestabilidad de sus representaciones científicas y dificultades para su profesionalización”, Universidad Nacional de Rosario, Rosario, 2003; Alicia Novick, "Planes realizados y proyectos inconclusos en la construcción de la ciudad moderna. Buenos Aires, 1900-1940”, Buenos Aires, Universidad de San Andrés, 2007.

5. Se realizó un excelente catálogo a cargo de Rigotti: Buenos Aires, un faro cosmopolita. El Plan Noel 1922/1925, Buenos Aires, Museo de Arte Hispanoamericano Issac Fernández Blanco, 2019.

6. Ambos tienen una producción muy extensa, en la que pueden destacarse: Arturo Almandoz, Modernización urbana en América Latina. De las grandes aldeas a las metrópolis masificadas, Santiago de Chile, Instituto de Estudios Urbanos y Territoriales, PUC Chile, 2013; Juan José Martín Frechilla, Planes, planos y proyectos para Venezuela: 1908-1958. (Apuntes para una historia de la construcción del país), Caracas, Universidad Central de Venezuela, 1994. 
del urbanismo, mientras que el primer volumen publicado por la red de pesquisa, Urbanismo no Brasil 1895-1965, sin ser exactamente una historia general, ofrece algo más: una suerte de enciclopedia abarcante que funciona como sostén de toda historia. Por añadidura, ya hace varios años viene resultando notorio en Brasil el interés por entender la historia del urbanismo nacional en el marco regional, lo que ha llevado a expandir los estudios invirtiendo drásticamente la dificultad tradicional del pensamiento brasileño de incluirse en América Latina -un interés presente con claridad en varios de los artículos del libro, que toman las redes latinoamericanas como el soporte natural desde el cual las políticas brasileñas deben ser comprendidas, lo que se está logrando a partir de sólidas investigaciones.

Puestos a tratar de entender las razones de esta diferencia cualitativa y cuantitativa de la historiografía del urbanismo en Brasil, logro identificar al menos dos. La primera, el eficiente sistema de posgrado extendido a todo el país, articulado con una institucionalización avanzada de los campos disciplinares del urbanismo y la planificación (centros especializados en varias universidades, asociaciones de investigadores con encuentros regulares que favorecen la creación de grupos y redes, proyectos temáticos con financiación estadual o federal, etc.), de modo que se ha podido capitalizar la formación sistemática de investigadores con un programa claro de problemáticas elaborado colectivamente. La segunda razón, la vigorosa tradición del planeamiento en Brasil: como señaló José Lira en la presentación del libro, la mayoría de las integrantes de la red urbanismobr comenzó su carrera dentro del campo de la planificación antes de haberse volcado a escribir su historia -y el uso del femenino como genérico en esta afirmación no es secundario en la hipótesis de Lira, ya que nos hizo advertir que en esa mayoría, las mujeres son a su vez mayoría, en un campo profesional como el de la arquitectura, del que provienen todas, hegemónicamente masculino. ${ }^{7}$ Lo cierto es que la orientación hacia la historia del urbanismo impulsada por esa tradición vigorosa de la planificación no sólo admite, sino que se enriquece con enfoques sistemáticos, algo no sencillo de extender a otros campos vecinos de estudio. La historia de la ciudad, por caso, también tiene un desarrollo importante en Brasil; sin embargo, no sería posible en este campo establecer el mismo tipo de contraste con lo que se hace en el resto de la región, por la sencilla razón de que es una perspectiva historiográfica que no favorece programas de investigación de vocación metódica; por el contrario, gana con los enfoques más idiosincráticos, con puntos de vista y selección de problemáticas irreductibles a un plan colectivo. El poderoso efecto de relevamiento comprehen-

7. Comentario de José Lira en la presentación del libro, Librería Tapera Taperá, Sao Paulo, 26 de octubre de 2019. Disponible en video en la página de youtube de la librería. 
sivo que el desarrollo de la historia del urbanismo genera en Brasil se apoya, así, en un aprovechamiento muy inteligente de una potencialidad intrínseca de esta especialidad disciplinar.

Ahora bien, pese a que el territorio de la historia del urbanismo en Brasil está tan bien cubierto, no cabe duda de que este volumen produce una nueva plataforma de conocimiento, tomando un período muy arduo y abordándolo audazmente desde lo que constituyó el núcleo mismo de su complejidad, las relaciones con la política. Por supuesto, esas relaciones existen siempre, necesariamente: también están muy presentes en el otro volumen de la red de pesquisa dedicado por completo a un período histórico, Urbanismo na Era Vargas, como demuestra el modo mismo en que el período fue definido. Pero al titular este nuevo libro con esa pareja cuya conjunción dista de ser unívoca, “urbanismo y política”, el grupo urbanismobr está mostrando su comprensión de que la década del sesenta no sólo demanda poner la política en el centro de toda consideración, sino también de que la noción misma de política debe ser explorada en su máximo espectro: como políticas públicas -que es como aparece con mayor frecuencia en el volumen sobre la Era Vargas-, pero también como conflicto de clases, como disputa entre público y privado, entre técnica e ideología; como retórica del poder y como imaginación social. El libro recorre todas estas acepciones sin abandonar un centro lógico y necesario en la cuestión institucional.

El vínculo con el período varguista está, por cierto, muy presente, al punto de que Maria Cristina Leme plantea en la introducción la necesidad de incluir la década de 1960 en un ciclo mayor, que arranca para el urbanismo en 1930. Pero ¿cómo pensarlo?, se pregunta: ¿cómo un ciclo de largas continuidades entre dos dictaduras, interrumpidas brevemente por un período de reformas radicales?; ¿o puntualizando en la alternancia entre democracia y dictadura, marcada a fuego por el golpe de 1964? Y si bien la mayor parte de los trabajos del libro toma en algún tramo ambos enfoques, me parece claro que lo más innovador que propone el conjunto es obligarnos a pensar una serie de notables continuidades que permiten ver el crescendo de la institucionalización del urbanismo y el planeamiento y, simultáneamente, la serie de contrastes y trágicas rupturas que convierten a la década del sesenta en Brasil en una suerte de monstruo bifronte (la propia introducción de Leme se titula "continuidades, contradições e rupturas"). Creo que en este aspecto reside la gran provocación intelectual e ideológica del libro y me voy a concentrar en ella en lo que resta de esta reseña, porque permite abrir una cartilla de cuestiones candentes para el desarrollo historiográfico.

Respecto de las continuidades, una de las principales lecciones que se extraen del libro es la imposibilidad de atribuirle carácter orgánico a las políticas públicas 
de cualquier gobierno, ni siquiera cuando se trata de una dictadura que, por definición, intenta imponer el unanimismo y eliminar la deliberación, pero que no puede evitar que los diversos sectores del estado (por no hablar de las diferentes regiones del país) funcionen con lógicas relativamente autónomas, animadas por dinámicas de larga duración que se entrelazan complicadamente con los cambios coyunturales. En este sentido, son emblemáticos los itinerarios de dos instituciones clave analizadas en varios capítulos: el Instituto Brasileiro de Administração Municipal (Ibam), que había sido creado en 1952 y siguió presidiendo la gran movilización municipalista después del golpe de 1964, y el Serviço Federal de Habitação e Urbanismo (Serfhau), creado por la dictadura pero que parece venir a realizar, como demuestra Sarah Feldman en un estudio ejemplar, una "reconfiguración del campo profesional” por la cual se había pugnado en los años anteriores. Rodrigo de Faria sintetiza bien estas cuestiones cuando escribe que "o entendimento é de que o golpe de 1964 não anulou ou silenciou o campo de planejamento urbano e as propostas no âmbito das políticas urbanas”, aunque se trató, como aclara, de “continuidades no homogêneas”.

La diversidad del Estado, su porosidad ideológica, la dificultad de vincular sin mediaciones sus políticas sectoriales con los principios generales de los gobiernos, la inercia que muchas áreas de actuación experimentan frente a los cambios bruscos de otras, son, por cierto, características generales que deberían formar parte del protocolo de estudio de las políticas públicas de todos los períodos dictatoriales de la región. Pero no deberían disolver una especificidad de la dictadura brasileña en el contexto sudamericano que emerge clara de la lectura del libro: mientras que los golpes de estado en Chile (1973) y Argentina (1976) se realizaron ya en los albores de la retracción conservadora y el avance del neoliberalismo en el mundo, la idea de modernización del régimen militar brasileño no se había alienado todavía de funciones e instituciones clásicas del estado de bienestar (algo que también ocurrió en el golpe de 1966 en la Argentina, una "dictadura desarrollista" aunque bastante más efímera que la del Brasil). Hay que recordar que si bien Thatcher y Reagan -los nombres que llegaron a identificar el desmontaje del estado de bienestar-asumieron sus gobiernos en 1979 y 1981 respectivamente, su llegada fue anunciada por toda una serie de cambios que arrancaron con el quiebre del optimismo desarrollista en la crisis petrolera de 1973. Podemos retomar, entonces, la idea del "largo siglo XX urbano" para precisar que el golpe en Brasil se dio cuando todavía no se advertían las señas de su desgaste, los indicios del final de la expansión (inseparable del protagonismo estatal en la vida social y el territorio, aunados en el credo planificador), que ya en la segunda mitad de la década de 1970 iban a ser cada vez más abrumadores, poniendo en cuestión todo su sostén ideológico y 
su entramado institucional. El impulso desarrollista de la dictadura brasileña va a encarnar tanto en instituciones clave de la planificación como en los posgrados que surgen entonces (como se ve en varios artículos del libro), manteniendo la inercia expansiva incluso cuando el clima internacional cambie en la segunda mitad de la década de 1970. El análisis de figuras como Diogo Lordello de Mello, del Ibam, o Harry Cole -a quien se puede encontrar en el artículo sobre Recife de Virginia Pontual cumpliendo un rol destacado en la política de desarrollo del prefecto Arraes y en otros varios como protagonista en las instituciones planificadoras de la dictadura-, muestra desde ángulos muy diferentes las específicas "continuidades no homogêneas" de la situación brasileña, por no hablar de la persistencia de los equipos de Economía y humanismo y de sus premisas teóricas e ideológicas en la formación de los técnicos municipales en urbanismo durante la dictadura, según aprendemos en el artículo de José Francisco Bernardino Freitas. Continuidades que abren una serie de desafíos al análisis, como el problema de pensar juntos la experiencia de la persecución, la cesantía e incluso la clandestinidad padecida por tantos arquitectos, urbanistas o planificadores, y la evidencia del rol de muchos de ellos en diferentes instancias de las políticas de la dictadura, como consultores privados, como asesores en gobiernos municipales, como referentes teóricos en esos cursos universitarios de posgrado que iban creándose.

A su vez, los principales lineamientos de políticas urbanas post 64 que se desprenden del libro vienen a mostrar la necesidad de distinguir entre medidas tomadas por una dictadura y medidas dictatoriales -una distinción que, cuando hablamos de esa particular componente de la política que remite al terrorismo estatal, resulta fundamental para el juicio-, especialmente si las colocamos en relación con transformaciones que estaban ocurriendo en el mundo, no ligadas a procesos autoritarios. Por ejemplo, tomemos la búsqueda de privatización del sector del planeamiento, en el doble sentido en que aparece en diferentes partes del libro: como creación de un mercado de planificadores con una creciente privatización de los encargos públicos, y como apertura al mercado en la producción de vivienda pública y loteos. Lo primero es algo que Cole logra dinamizar desde el Serfhau, pero también lo encontramos en la década de 1970 en México, cuando se vuelve obligatorio por ley que cada municipio tenga un plan urbano, generando una demanda de profesionales que las plantillas estatales no podían satisfacer. Y la apertura al mercado en la producción de vivienda propiciada por el Banco Nacional de Habitação -creado por la gestión de Roberto Campos al frente del Ministerio de Planejamento durante los primeros años de la dictadura-, era algo que ya había puesto en práctica esa figura tan singular que fue Carlos Lacerda, cuya experiencia de gobierno, muy bien analizada por Vera Rezende en su capítulo sobre Rio, no 
podría ser definida como la antesala de las políticas del régimen militar. Quiere decir que son medidas cuya intelección no debería ser afectada directamente por la dimensión ominosa y represiva que la dictadura manifiesta en tantos otros planos de la vida brasileña, aunque el análisis deba restablecer la relación con el régimen en el punto pertinente, mostrando el modo en que éste se expresa también en las medidas específicas o, si no en ellas, en las formas en que fueron aplicadas y en los efectos que produjeron en ausencia de debate público y con las enormes limitaciones a cualquier participación social que la represión causaba. Son cuestiones clave que este libro permite comenzar a evaluar bajo una nueva luz, mostrando todas las dificultades que supone y todos los desafíos que el período le pone al pensamiento histórico y crítico.

Respecto de las rupturas, el panorama que surge es más complejo todavía, porque creo advertir en el libro una dualidad: si las enormes dificultades inherentes al tratamiento de las políticas de la dictadura obligaron a tomar grandes recaudos analíticos, posibilitando tanto el hallazgo de las continuidades institucionales en la producción del campo de la planificación como la detección de las contradicciones en el seno del régimen militar, todavía es muy difícil avizorar, por contraste, el afianzamiento de un punto de vista crítico que permita tomar distancia de la experiencia de la radicalización -lo que sin duda afecta también las posibilidades de evaluar con mayor precisión su remoción y reemplazo. Ciertamente, la cancelación brutal de esa experiencia llama a la empatía, sobre todo desde un presente que en muchos aspectos parece retrotraernos a aquel momento terrible. Pero quizás por eso mismo sea tan importante la reflexión crítica sobre ella, apostando a que pueda contribuir con los debates sobre un reformismo urbano contemporáneo.

¿Cómo analizar los límites y contradicciones propios de los postulados progresistas tal cual se fueron disponiendo en el tablero de los años sesenta? ¿Cómo mensurar políticamente las propuestas urbanísticas en un período histórico tan crispado, los debates disciplinares, las ideas sobre la ciudad en una coyuntura tan compleja? ¿Cómo sustraerse del encanto que genera la épica de la revolución? No creo que haya una forma universal de hacerlo, en base a algún tipo de vara política abstracta y absoluta: por el contrario, esos juicios deben ser cada vez motivo de elaboración historiográfica y política, de nuevos debates que alimenten la reflexión sobre el pasado y el presente. En este caso, podría ser de ayuda utilizar como hipótesis de lectura un enunciado político que tiendo a ver como base implícita de la historiografía del urbanismo, y que podría formularse así: si entender que la arquitectura forma siempre parte de las tramas del poder fue un paso fundamental para desarmar las mistificaciones ideológicas del "Movimiento Moderno" como revolucionario -o incluso democrático-per se, la clave principal para una historia crítica 
del urbanismo fue desmontar la relación de necesidad entre Plan y Socialismo planteada por la cultura arquitectónica radical de entreguerras. Manfredo Tafuri mostró esa relación de necesidad como un malentendido vanguardista, analizando el modo en que la reestructuración capitalista de la década de 1930 internalizó el plan como forma constitutiva de operación racional; pero quien extrajo sus consecuencias para una historia del urbanismo fue, en mi opinión, Giorgio Piccinato en su libro sobre la emergencia del urbanismo alemán, obra seminal editada en Roma en $1974 .^{8}$

Piccinato no trabajó sobre las vanguardias, sino sobre un período tabú para la doctrina del "Movimiento Moderno", el urbanismo profesional de fines de siglo XIX y comienzos del XX (que muchos comenzaban a llamar "moderno"), generando un doble efecto: mostró que ese urbanismo había sido un modo muy eficaz de gestión de la ciudad capitalista que incluyó dosis altas de reformismo (en rigor, se trató de la realización institucional-urbana del reformismo social finisecular), y puso en evidencia el carácter utópico del urbanismo modernista (en el sentido despectivo de la expresión con que el marxismo se había referido al "socialismo utópico”), que impostó ideológicamente el papel revolucionario del Plan. Por supuesto, escribiendo a comienzos de los años 1970 Piccinato era bien consciente de que el urbanismo del "Movimiento Moderno" como tal ya no era dominante: su invocación fue contra una tradición de historia de la arquitectura y del urbanismo, en plena actividad, que había levantado el primado moral de las corrientes utópicas, armando un relato épico que conectaba las propuestas de ciudades obreras filantrópicas en el siglo XIX con el modelo de la ciudad jardín y a éste con la doctrina CIAM; a ese relato, le contrapuso una historia disciplinar de lo "realizado concretamente en la sociedad industrial”, es decir, aquello que desde aquel primado moral había sido imposible siquiera de reconocer como una práctica específica. ${ }^{9}$ Por lo tanto, esa distinción

8. Giorgio Piccinato, La costruzione dell'urbanistica. Germania, 1871-1914, Roma, Officina, 1974. Sobre la mención a Tafuri, ver por ejemplo "El socialismo realizado y la crisis de las vanguardias" [1970], en AAVV, Socialismo, ciudad, arquitectura. URSS 1917-37, Comunicación, Madrid, 1973.

9. La costruzione dell'urbanistica, op. cit., p. 150. Hay que recordar que el reconocimiento historiográfico de ese "urbanismo moderno", o profesional (Benevolo lo llamó "clásico"), estaba recién comenzando, en una práctica muy nítida contra el relato más asentado de la historia de la arquitectura moderna. El primer texto que abrió ese juego fue el de George R. Collins y Christiane C. Collins en el libro que organizaron sobre Sitte, Camillo Sitte: The Birth of Modern City Planning, Nueva York, Random House, 1965; este libro fue también fundador de un formato que remarcó la voluntad filológica de la nueva historiografía del urbanismo: amplios estudios introductorios a textos clásicos que se reeditaban después de mucho tiempo o se traducían por primera vez. El libro de Piccinato sigue el formato, publicando su largo estudio como introducción de una antología de textos de urbanistas alemanes organizada por Donatella Calabi, una de las historiadoras que seguramente más contribuyeron con la generalización de esa impronta filológica (iba a publicar al año siguiente el Catálogo de las exposiciones de urbanismo de Berlín y Dresde [1910 y 1911-12], de Werner Hegemann, así como su libro 
podría ayudarnos aquí a identificar la matriz duradera de dos actitudes en la historia del urbanismo: la de una planificación reformista, que acepta el orden social y las reglas de juego más generales del mundo capitalista, proponiendo en todo caso una amortiguación de sus conflictos y contradicciones más evidentes, y la de una planificación utópica, anticipatoria de un orden social nuevo, que organiza sus propuestas en torno de una crítica radical a la propiedad privada del suelo. ${ }^{10}$ Y ni siquiera es necesario acordar con la valoración político-ideológica que Piccinato acordó a cada una, para coincidir en que se trata de posiciones antagónicas y, especialmente, que liberar al urbanismo profesional de la vara de medida puesta desde el primado moral utópico fue decisivo en la construcción de la historiografía del urbanismo.

También en Brasil: no cabe duda revisando toda la producción de la red urbanismobr, que el rasgo definitorio en la estructuración del campo disciplinar ha sido el foco en el estudio y la ponderación minuciosos del urbanismo profesional de las primeras décadas del siglo XX en sus más diversas vertientes, de las más pragmáticas a las más doctrinarias, de las más reformistas a las más conservadoras. ${ }^{11}$ Este es otro de los elementos que establece la continuidad entre el volumen de la Era Vargas y el de los años sesenta, pero en este último, el abordaje de algunas posiciones más radicales parece colocarse en un paradigma diferente, generando disonancias en el cuadro general en las que vale la pena detenerse. Hay dos episodios en la experiencia de la radicalización del pensamiento urbanístico de los sesenta tratados con bastante detalle en el libro, donde esto aparece con mayor

Das steinerne Berlin [1930], el primero junto con Marino Folin, con quien ya había colaborado en 1972 para una antología de Eugène Hénard).

10. No olvido que el reformismo liberal en la ciudad se desarrolló bajo el signo de una paradoja fundacional: no hay reformismo posible sin afectar la intangibilidad de la propiedad privada -pilar del liberalismo como doctrina. Esta paradoja está presente desde las expropiaciones del Prefecto Haussmann hasta las regulaciones edilicias y la propia noción de plan regulador -anticipatorias de una idea de estado interventor como luego se iba a consolidar en los regímenes de Bienestar. Pero la diferencia con la actitud utópica es que se trata de críticas más o menos puntuales al rol de la propiedad privada como obstáculo para una racionalización de las funciones urbanas, que, si bien suponía en lo inmediato la limitación del derecho de propiedad, proponía no sólo una distribución social de los beneficios más equitativa (cumpliendo ese rol amortiguador del que habla Piccinato), sino también la maximización a más largo plazo de la productividad capitalista de la ciudad.

11. Es más: me atrevo a sugerir que esa marca de origen podría explicar la dificultad de estudiar Brasília como parte de la historia del urbanismo, y ya no sólo de la historia de la arquitectura modernista o de la sociología urbana -hay ya varios trabajos que lo hacen, por cierto, pero el desbalance en la bibliografía sigue siendo notorio. Esa dificultad muestra un remanente claro en este libro: el capítulo sobre Brasília, de José Geraldo Simões Júnior, se coloca en la ya larga tradición de crítica sociológica, como si sólo se pudiese examinar la relación entre el urbanismo y la política en el caso de la nueva capital volviendo a denunciar los procesos de segregación urbana sobre los que hay una extensa literatura. 
claridad: el Seminario de Habitação e Reforma Urbana (s.HRu), realizado en Rio de Janeiro y São Paulo en julio de 1963, que aparece mencionado en varios capítulos pero al que Ana Fernandes dedica un exhaustivo análisis; y la gestión del gobierno municipal de Miguel Arraes en Recife, al que Virginia Pontual dedica un estudio que busca calibrar las rupturas que produjo en el pensamiento planificador el golpe de 1964 .

Fernandes despliega la enorme riqueza de posiciones y pertenencias socio-políticas e ideológicas representadas en el s.HRu, y en un gran aporte para la comprensión de las claves políticas con que la planificación se pensaba en el período, demuestra con contundencia el origen cubano y revolucionario de la noción de “reforma urbana”. Pero ¿cómo evaluar esa variedad de posiciones? El modo que toma este artículo es colocar todo el amplio espectro de reformismos en el curso de una gran tradición, conformando una única "trama de reforma urbana” que se fue entrelazando desde el comienzo de la construcción de una agenda estatal en la década de 1920, consolidada desde 1930 y potenciada en la década de 1960 con la acción de la sociedad civil y la inspiración de la revolución cubana: un entramado reformista cuya apoteosis se verifica en el s.HRu, con el protagonismo institucional de los arquitectos, quebrado inmediatamente después por el golpe. Esta fusión produce dos efectos complicados para el análisis: por una parte, al reunir todas las posiciones en el mismo entramado reformista, no sólo se elude una contrastación que permitiría identificar diferencias y conflictos entre ellas, sino que se fuerza una consistencia de esa "pauta reformista" que no es, en rigor, sino una proyección retrospectiva del golpe del 64, convirtiendo este hecho en el corte absoluto que las otras hipótesis sobre el período en el libro discuten. Por otra parte, al poner como punto de llegada de esa tradición la reforma urbana de inspiración cubana, definida como un avance objetivo hacia "una perspectiva más democrática”, está invistiendo a todo el pensamiento planificador de una tensión natural hacia la gran conquista diferencial lograda en Cuba -la liberación progresiva del acceso al suelo urbano-, llevando, por ende, a que toda esa tradición se evalúe desde tal conquista. Fernandes analiza con mucha perspicacia el proceso de la reforma urbana cubana como el último eslabón reformista que daría paso a una política ya efectivamente revolucionaria en la isla. En los términos del vocabulario comunista, en efecto, la reforma urbana nació como un espejo de la agraria, consideradas ambas tareas de la revolución democrático-burguesa, no socialista todavía, pero que de todos modos precisaron de una revolución para implantarse. Por lo tanto, ¿es útil para la historiografía juzgar el conjunto de la tradición planificadora en Brasil (o en cualquier otro país latinoamericano) desde ese resultado que en Cuba fue una 
emergencia de la revolución (y que desde 1961, con la sovietización creciente de la política y la economía, se radicalizaría en toda otra serie de expropiaciones y colectivizaciones)?

Por ejemplo, en varios capítulos del libro se menciona un seminario convocado por el Centro Interamericano de Vivienda -CINVA- en Bogotá, en 1958, que dio lugar a un documento titulado "Carta de los Andes", presentado como un episodio clave en la institucionalización del pensamiento planificador en Brasil. Es decir, se trata de un evento cuyas proyecciones y efectos son contemporáneos a los de la revolución cubana y su reforma urbana. Sin embargo, la "Carta" es una codificación de los postulados de la "planificación democrática" que impulsaban las redes panamericanas con fuerte respaldo norteamericano, ejemplo muy claro del carácter "amortiguador" de los conflictos generados por la ciudad capitalista que se autoasigna el urbanismo profesional: esto se ve con nitidez en el apartado sobre "control de la especulación de la tierra" que plantea medidas impositivas de recuperación de la plusvalía e intervención reguladora de los precios, pero a años luz de cualquier propuesta de eliminación progresiva de la propiedad privada como la que llevaría adelante la "reforma urbana". ¿Es simplemente que los que se reunieron en Bogotá fueron más tibios que los cubanos, o hay diferencias doctrinarias en la forma de pensar el planeamiento que el análisis debe tomar en cuenta? Volviendo al texto de Fernandes, cuando luego de un cuadro preciso de los reformismos europeos de fines del XIX y comienzos del XX ella afirma que es posible considerar a la reforma urbana cubana como "la más próxima de la realidad latinoamericana y brasileña”, ¿es exactamente así, o habría que pensar que había otros sectores de esa realidad -en lo que hace al pensamiento urbano, al menos- que estaban más cerca de Bogotá y de otros reformismos que podían llegar a ser incluso antagónicos? ¿No habría que incluir en el cuadro reformista las derivas a lo largo de la primera mitad del siglo XX del reformismo liberal norteamericano, con su sólida tradición de reform clubs tan influyente en el movimiento regionalista que, a su vez, tendió lazos determinantes en las redes panamericanas? ¿Y qué decir de los vínculos estrechos entre el reformismo panamericanista y el catolicismo de base? Porque si bien sabemos que hubo acercamientos importantes entre catolicismo y marxismo en el proceso de radicalización, también seguirían teniendo conflictos inconciliables respecto de políticas sociales y urbanas: mientras buena parte del social-catolicismo dio un respaldo compacto a las políticas de la Alianza para el Progreso y el panamericanismo, el comunismo las enfrentó con el ardor de la Guerra Fría. Digamos, por poner sólo un ejemplo, que la presencia de un reformista católico como José Arthur Ríos en los primeros tramos de la gestión de Carlos Lacerda en Rio de Janeiro, a cargo ni más ni menos que de la cuestión 
de las favelas, puede encontrar en ese mapa político de los reformismos algunas claves importantes: la adhesión de Lacerda a la Alianza para el Progreso es muy coherente con una política para las favelas que las redes panamericanas -con ese centro neurálgico de difusión técnico-ideológica que fue el CINVA, muy asimilable a los principios de Economía y Humanismo- también auspiciaban desde la década de 1940, cuando Puerto Rico se volvió el modelo insuperable para los programas de autoconstrucción en todo el continente.

En ese sentido, hay varios indicios que permitirían pensar que los arquitectos y los planificadores en América Latina no tuvieron el mismo entusiasmo ante las reformas cubanas: si los arquitectos se volvieron sus difusores incondicionales al menos desde que las pudieron visitar in situ en el Congreso de la UIA en La Habana de 1963, los planificadores parecen haber esperado al menos una década más para prestarles atención, hasta la caída del gobierno de Allende en Chile, uno de los grandes laboratorios de la planificación reformista, porque recién allí cayeron las últimas expectativas de practicar la reforma sin la mediación de una revolución social y política. ${ }^{12}$ No pretendo establecer alineamientos estrictos entre ideología y profesión, y menos que menos separaciones tajantes entre profesiones, ya que la mayoría de los planificadores también provenía de la arquitectura, y la extensión "natural" hacia el urbanismo es posiblemente la marca generacional más fuerte en la autorepresentación progresista de la arquitectura. Además, tenemos todavía pocos estudios que analicen la componente ideológico-partidaria en la organización del mundo del pensamiento urbano en el período, a pesar de haber sido tan determinante de muchos de los lineamientos tomados entonces (sin duda, el capítulo de Fernandes ofrece un gran avance en esta dirección). Asumiendo todas esas limitaciones, creo que puede ser interesante someter a prueba la hipótesis de una suerte de bifurcación ideológica en las formas de socialización política de la arquitectura y la planificación, con una dominante comunista en las primeras y una presencia mayor del socialcristianismo en las segundas. Pero incluso sin acordar con esta hipótesis, ¿no habría que incorporar en el análisis la política comunista en el mundo de los arquitectos como una política más, y no como una suerte de vara de medida para las demás propuestas? De lo contrario, se vuelve a proponer como necesidad la relación sustancial entre Plan y Socialismo, dejando en la sombra una vez más toda la vertiente profesional del urbanismo, antiutópica, que vino analizando con tanto detalle la historiografía.

12. He presentado esta hipótesis hace ya tiempo en mi artículo “A produção da 'cidade latinoamericana”, Tempo Social. Revista de Sociología da USP, vol. 17, n. 1, Universidade de São Paulo, São Paulo, junio 2005. 
En el análisis de la experiencia del gobierno Arraes en Recife (un gobierno de Frente Popular formado por comunistas, socialistas, trabalhistas y varios sectores más de la izquierda independiente y del nacionalismo) también nos encontramos con la aplicación de una similar vara de medida, que en este caso se pone en el "pensamiento de vanguardia”, una denominación propuesta por la propia Política de desenvolvimento do Recife metropolitano que lanza el gobierno en 1962, y que Pontual define como un pensamiento opuesto al de las élites en el poder, lo que en términos del plan que analiza significa que buscaba entender la miseria como un elemento no inmutable, para cuya transformación era necesario romper con las estructuras de dominio establecidas desde siempre en la región. Pero si así se define ese "pensamiento de vanguardia" en general, siguiendo a la autora advertimos algo muy interesante para los problemas de la relación entre urbanismo y política: mientras esa vanguardia comparece en toda su radicalidad en las áreas de la Política de desenvolvimento que quedaron en manos de los sectores comunistas del gobierno (especialmente en la sección sobre la Reforma agraria, donde se plantea la necesidad del control de la propiedad privada de la tierra), las medidas específicamente urbanísticas del plan "deram menor ênfase à quebra das regras institucionais vigentes”. Pontual explica ese contraste en que el plan urbanístico estuvo a cargo de Antônio Bezerra Baltar y Harry Cole (uno del Partido Socialista Brasileiro (PSB) y el otro ligado a las corrientes políticas conservadoras, nos aclara), que le dieron un tono menos radical dentro de los lineamientos del urbanismo anglosajón que ambos seguían -y que era dominante en el pensamiento internacional del momento.

Ahora bien, ¿por qué la propuesta urbanística quedó en esas manos? ¿Por la necesidad de contentar a las diferentes partes de un frente político tan heterogéneo? ¿Por el prestigio de una figura como Baltar, aunque sus ideas remitían más al reformismo de la "Carta de los Andes" (de la que era firmante, según nos enteramos por el texto de Sarah Feldman) que al cubano que podía entusiasmar a los sectores comunistas (hegemónicos en el gobierno, nos dice Pontual)? ¿Por los antecedentes técnicos de Cole, aunque sus ideas liberal-conservadoras debían ser inocultables? ¿O quizás porque entre las urgencias revolucionarias, el comunismo no tuvo tiempo ni capacidad de precisar una propuesta urbanística a la altura del radicalismo presente en otras secciones de la Política de desenvolvimento? Quizás sea imposible responder de manera precisa, y es muy probable que haya que combinar varias de esas razones. Pero el foco excluyente del artículo en la identificación de los contrastes entre el momento anterior y posterior al golpe de 1964 no favorece avanzar en ellas: la autora nota bien las disonancias del pensamiento urbanístico en relación con el resto del "pensamiento de vanguardia”, por supuesto, pero aquel 
foco la lleva a mantener la idea de un bloque político más o menos homogéneo de cada lado de esa fecha parteaguas. Y como lo más avanzado dentro del bloque progresista pareciera dar la medida del resto, la sección urbanística del plan queda apenas como déficit, como carencia, resultado de las pervivencias de una ideología atrasada, y no como una tradición intelectual e ideológica en conflicto. Si pensamos en la historiografía que abordó otras situaciones de agitación revolucionaria, como la República de Weimar o la Viena socialdemócrata, podemos percibir la importancia del análisis de los conflictos, de la pregunta acerca de las posibilidades y limitaciones de actuación del urbanismo en contextos maximalistas -un tipo de interrogación que supone analizar cuestiones como la financiación de las políticas de reforma, sus alternativas, las disputas con los sectores tradicionales de poder pero también con los sindicatos y los partidos políticos, etcétera. De modo análogo, queda planteada la pregunta crucial sobre los límites propios del "pensamiento de vanguardia” en el terreno urbanístico, lo que implicaría tomar ese pensamiento como una propuesta política entre otras, en condiciones de ser analizada y sometida a debate desde el punto de vista de la historia del urbanismo, y no como punto de llegada de la radicalización democrática, una epifanía socio-política que sólo cabe celebrar como el "último namoro da cidade com a revolução" (de acuerdo a la cita de Chico de Oliveira recordada en el capítulo).

¿Qué conflictos había allí anidados, qué atolladeros para pensar posibles encarnaciones político-urbanísticas de las tradiciones del reformismo? ¿No sería conveniente analizar el proceso de radicalización como un campo de debate entre cosmovisiones enfrentadas, a veces duramente, que el golpe del 64 viene a reprimir pero no puede cancelar por completo, aunque sí desfigura y reordena en sus alineamientos, razón por la cual esas cosmovisiones se encuentran luego no sólo dispersas en las proclamas de las instituciones opositoras y en las propuestas de grupos alternativos, sino también metamorfoseadas y en astillas, pero reconocibles, en los intersticios de algunas políticas del gobierno militar?

Estos comentarios, por cierto, no suponen ninguna demanda al libro, sino por el contrario, son posibles gracias a él. El libro aborda por primera vez con tal amplitud de miras un período plagado de desafíos para la comprensión histórica. Lo hace con rigor analítico y compromiso con el conocimiento, produciendo un nuevo andamiaje para las historiografías especializadas en el pensamiento urbano en toda la región. Justamente por eso, opté por detenerme en las zonas que me resultaron más innovadoras, pero también en sus nudos más problemáticos, eludiendo una reseña más metódica de cada uno de los textos, a los que evidentemente no les he hecho justicia. Pido disculpas por eso: es muy ingrato reseñar libros colectivos, especialmente cuando cada uno de los artículos que lo componen, como ocurre en 
este caso, tiene detrás un gran trabajo y presenta hipótesis sustanciosas que merecerían el desarrollo de discusiones específicas. ${ }^{13}$ A cambio, me pareció necesario describir a trazos más gruesos el nuevo paisaje de los años sesenta al que este libro permite asomarnos, esos años rugientes que apenas ahora estamos comenzando a abordar con los instrumentos de la historiografía del urbanismo.

13. Además de los artículos mencionados a lo largo de la reseña de Maria Cristina Leme ("Urbanismo e política no Brasil: continuidades, contradições e rupturas"), Rodrigo de Faria ("O planejamento urbano no Brasil entre a democracia e o autoritarismo: uma interpretação em quatro dimensões”), Ana Fernandes ("Reforma urbana no Brasil: inquietações e explorações acerca de sua construção enquanto campo e política”), Sarah Feldman (“O Serviço Federal de Habitação e Urbanismo (Serfhau) e a reconfiguração do campo profissional do urbanista”), José Francisco Bernardino Freitas (“Contradições na política educacional no Estado de Segurança Nacional: uma experiência singular”), Virginia Pontual ("Planejamento e política na cidade do Recife: sofreu essa relação ruptura com o Golpe Civil-Militar de 1964?”) y Vera Rezende ("Planejamento, gestão e obras na Guanabara: iniciativas e conflitos no Governo Carlos Lacerda”), completan el libro los siguientes estudios: José Geraldo Simões Júnior, "Brasília: modernidade urbana, clandestinidade e segregação socioespacial”, Marlice Nazarteh Soares de Azevedo, "Niterói em 1960: uma capital de porte médio em conflito", Eneida Maria Souza Mendonca, "Reestruturação portuária e a construção institucional do planejamento da Grande Vitória”, Célia Ferraz de Souza, "As instituições do planejamento urbano no Rio Grande do Sul”, Maria Soares de Almeida, "O planejamento metropolitano no Rio Grande do Sul”, y Fábio José Martins de Lima, “O pensamento e as práticas do urbanismo e do planejamento urbano em Minas Gerais”. 


\section{Adrián Gorelik}

Arquiteto e doutor em história pela Universidade de Buenos Aires. Investigador independente do Conselho Nacional de Investigações Científicas e Técnicas da Argentina e professor titular da Universidade Nacional de Quilmes, onde dirige o Centro de História intelectual.

Email: adrian.gorelik@gmail.com

Submissão: 5 de novembro de 2019.

Aprovação: 14 de fevereiro de 2020.

Como citar: GORELIK, A. El pensamiento urbano en los años rugientes. Revista brasileira de estudos urbanos e regionais. v.22, E202007, 2020. DOI 10.22296/2317-1529. rbeur.202007

Artigo licenciado sob Licença Creative Commons CC BY-NC 4.o. https://creativecommons.org/licenses/by-nc/4.o/deed.pt_BR 